\title{
IGNITION OF WATER COAL PARTICLES COATED WITH A WATERFILM IN THE STREAM OF HIGH-TEMPERATURE ENVIRONMENT
}

\author{
Semen Syrodoy ${ }^{1 \mathrm{a}}$, Nadezhda Gutareva ${ }^{1}$, Ksenia Bugaeva ${ }^{1}$, Roman Taburchinov ${ }^{1}$. \\ ${ }^{1}$ National Research Tomsk Polytechnic University, 634050 Tomsk, Russia
}

\begin{abstract}
The characteristics and conditions of the ignition of coal-water fuel droplets (WCF) in a surface coating with a thin layer of water last film have been determined experimentally. A significant impact on the dynamics of the water layer of the thermal preparation and ignition of the fuel particles has been established. It has been shown that the time of evaporation of water of the surface layer can take up to $50 \%$ of all of the induction period. The latter indicates the need to consider the existence of the surface of the film during the process modeling of ignition of coal-water particles.
\end{abstract}

\section{Introduction}

At present, renewable energy sources have been widely used such as wind power stations [1] or solar photovoltaic cells [2]. However, the application of such technologies is very limited due to the need to ensure long-term power plant power source (sunlight or constant wind). The latter is feasible only in certain and not large (square) areas of the world [3]. It is also worth noting that the efficiency of power generation (thermal or electric) renewable energy at the moment of time is low $(<30 \%)$ [4]. Therefore, we can say with confidence that in the near future (according to forecasts [8]), coal will remain the main energy resources. However, traditional methods of burning coal (e.g., a torch [5] or layers [6]) do not provide satisfactory indicators emissions of oxides of nitrogen and sulfur. Recent ones stimulate the creation and implementation of new (ecological and energy perspective), the so-called "clean" coal technologies. [7] Developed technical solutions (using a low-temperature plasma [8], the microwave energy [9], and the circulating fluidized bed [10]) that reduce emissions of toxic substances have not found wide implementation in the overall balance of heat and power generation, due to the high cost and complexity of the equipment. One of the most promising areas - the creation and implementation of new, environmentally "clean" fuel compositions such as hydrocarbon fuel. WCF is a homogeneous structure composed of finely dispersed coal and water with the addition of various additives and plasticizers. It should be noted that the mathematical and physical description of the complex basic physical and chemical processes of heat and mass transfer thermal preparation and ignition occurring in the intensive (high-speed and high-) heating is an actual (unresolved to date) task.

Current models [11-19] of ignition and combustion of coal-water fuel droplets are not considered from the point of view the possibility of the formation of particles WCF whose surface is covered with a water film. As the experiments [20] have shown, the probability of such a configuration is very high $(\mathrm{P} \geq 50 \%)$. It's safe to say that the ignition of such particles will be significantly different from the ignition of the same WCF drops without water film. Obviously, the high endothermic effect of evaporation and heat capacity of water will create a kind of energy "barrier", inhibiting the ignition of fuel. In connection with it, the analysis of the effect of water film on the ignition characteristics and conditions has high interest.

Experimental studies of ignition and burning WCF particles whose surface is covered with a water film is very complex due to the need for placement of funds in high-speed video fixation conditions the combustion chamber of the boiler unit. Therefore, there are no publications most likely at the moment in the scientific literature with the results of studies of the effect of the film of water on the conditions of ignition and burning WCF.

The purpose - experimental study of physical and chemical processes of heat and mass transfer occurring during thermal preparation and ignition WCF particles coated with a thin layer of water.

\footnotetext{
${ }^{\text {a }}$ Corresponding author : ssyrodoy@yandex.ru
} 


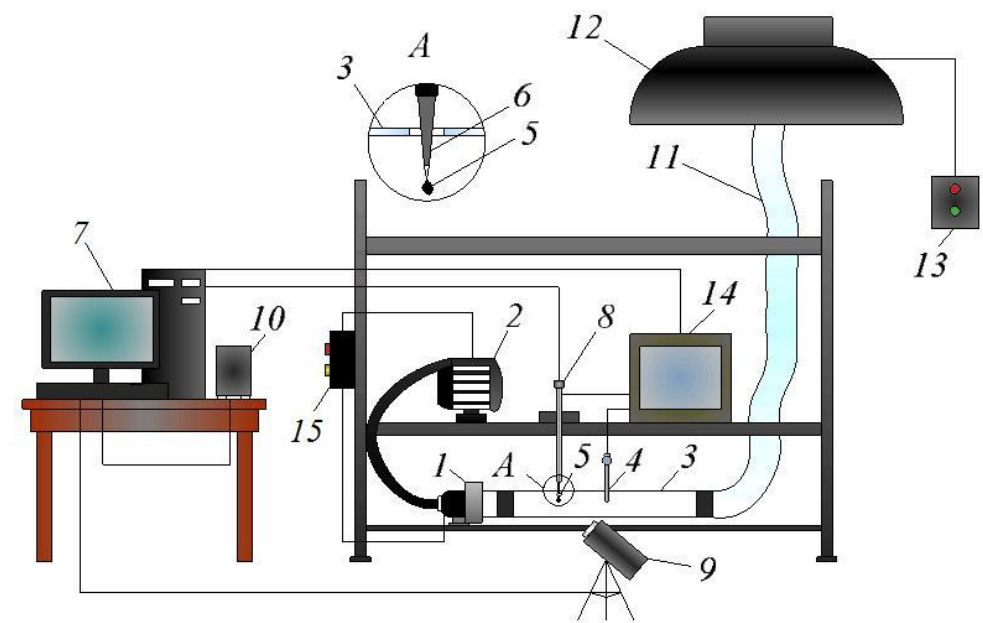

Figure 1. Schematic experimental setup: 1 - electric; 2- supercharger; 3 - a hollow cylinder; 4 - chromel-alumel thermocouple; 5 - fuel particles; 6 - needle thermocouple; 7 - the computer; 8 - pointing device; 9 - high speed video camera; 10 - analytical balance; 11 - flexible discharge pipeline; 12 - box ventilation system; 13 - remote control ventilation; 14 - multi-channel temperature logger (MRL); 15 - remote control heatinginjection system.

\section{The methods of the experiment}

The stand has been used (Fig. 1.), wherein there is a flow of heated in the electric heater (1) to a high temperature $(600 \div 900 \mathrm{~K})$ of the air supplied to the hollow cylinder (3) made of transparent quartz glass. The temperature of oxidant has been controlled by chromel-alumel thermocouple (4) (measurement error not less than 0,01K). A particle of coal-water fuel (5) hanging on the needle thermocouple (6), has been placed on the cylinder axis, remote-controlled from the computer (7) coordinate device (8). Video recording of processes of thermal preparation, ignition and combustion of coal-water fuel particles has been carried a video camera high-speed (9).

The experimental studies have been carried out for the composition of WCF -based coal grade "D" (Kuznetsk coal basin). The systematic error in the determination of basic parameters measured (ambient temperature $\left(T_{e}\right)$ and ignition delay time $\left.t_{i}\right)$ does not exceed $5 \%$. The confidence interval for $t_{i}$ at a confidence level of 0.95 does not exceed $18 \%$.

\section{Results experimental research}

Fig. 2 shows typical frames of video gram of thermal processes of preparation and ignition of the particles $\left(\right.$ diameter $\left.\mathrm{d} \approx 3.0 \cdot 10^{-3} \mathrm{~m}\right)$ coal-water fuel from coal grade " $\mathrm{D}$ " in the high-temperature environment $\left(\mathrm{T}_{\mathrm{e}} \approx 873 \mathrm{~K}\right)$. We can say that in the process of particle ignition WCF is a series of interconnected characteristic stages, with the prevalence in each separate process (inert heating, evaporation of the water film, "dewatering" of the base layer of fuel, thermal decomposition of the organic part, output and combustion of volatile, ignition and the burning of coke).

The analysis of typical frame video recordings show that the evaporation of the water film has a significant impact on the process of preparation and thermal ignition particles WCF. The total duration $\left(t_{c}\right)$ of the process of combustion has been about 39 seconds at $\mathrm{d} \approx 3 \cdot 10^{-3} \mathrm{~m}$ and the ambient temperature $\left(\mathrm{T}_{\mathrm{e}} \approx 873 \mathrm{~K}\right)$.

When in contact with the particles in the WCF inside the hollow cylinder (frame " $a$ "), it is a "tight" coal-water slurry surface is coated with a film of water. With a large increase in the frame " $a$ " you will notice the transparent areas.

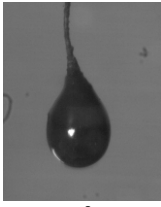

$\mathrm{t}=0 \mathrm{c}$

a

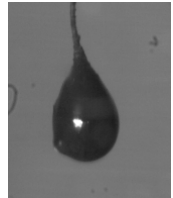

$\mathrm{t}=1,1 \mathrm{c}$

b

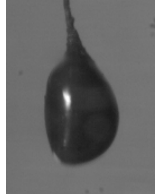

$\mathrm{t}=1,3 \mathrm{c}$

$c$

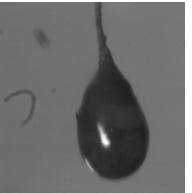

$\mathrm{t}=2,505 \mathrm{c}$ $d$

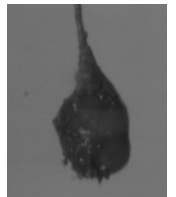

$\mathrm{t}=7,02 \mathrm{c}$ 


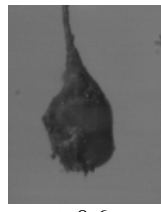

$\mathrm{t}=8,6 \mathrm{c}$

$f$

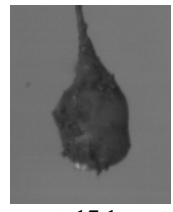

$\mathrm{t}=17,1 \mathrm{c}$

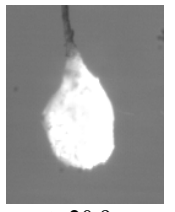

$\mathrm{t}=20,9 \mathrm{c}$

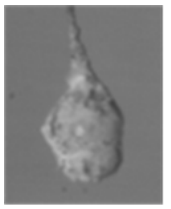

$\mathrm{t}=38,9 \mathrm{c}$

Figure 2. Personnel film of typical thermal processes of preparation and particle ignition of coal-water fuel from coal grade "D" under the surface of the final coating film of water.

The analysis frames " $b-d$ " shows that during the thermal treatment of the particle shape WCF undergoes intense changes in picture " $d$ " (at high magnification) can be seen even a weight of fuel ash. This is due to the boiling of water near the surface of the film. After evaporating the film, water coal agglomerate of "wrong" form is formed (frame " $e$ "). In the conditions of high heat a final water evaporation undergoes (frame "f") and thermal decomposition of the organic portion of the fuel. Further heating initiates inflammation particles (frame "g").

Fig. 3 shows the dependence of the delay time of ignition particles WCF water film evaporation and the ambient temperature. The particle diameter ranged $1,5 \cdot 10^{-3}<\mathrm{d}<2,5 \cdot 10^{-3} \mathrm{~m}$. The dependency analysis shows that the temperature of the environment greatly accelerates the ignition of coal-water particles. You can also say that the evaporation of the water film has a significant impact on the dynamics of thermal preparation and ignition of coal-water fuel particles. Since the evaporation time of the water layer is 20 to $30 \%$ of the total induction period. Accordingly, it is safe to say that the evaporation of the film is an integral part of the thermal preparation of fuel.

Fig. 4 shows the dependence of the delay time of ignition particles WCF and evaporation of the water film flow rate of the oxidizer. Ambient temperatures have been varied over a wide range $\left(673<\mathrm{T}_{\mathrm{e}}<873 \mathrm{~K}\right)$. The analysis of the curves shows that the speed of the incoming flow significantly affects the flow of basic physical and chemical processes of preparation and thermal ignition. It can be noted that with increasing velocity major oxidant temporal characteristics of the process are changed linearly. Similarly, figure 3 it can be noted that the evaporation of the water film plays an essential (a key) role in the processes of preparation and thermal particles ignition of coal-water fuel (in the whole range of flow rates of the oxidant stream). The time of film evaporation of water takes from 20 to $30 \%$ of the time of initiation of combustion.

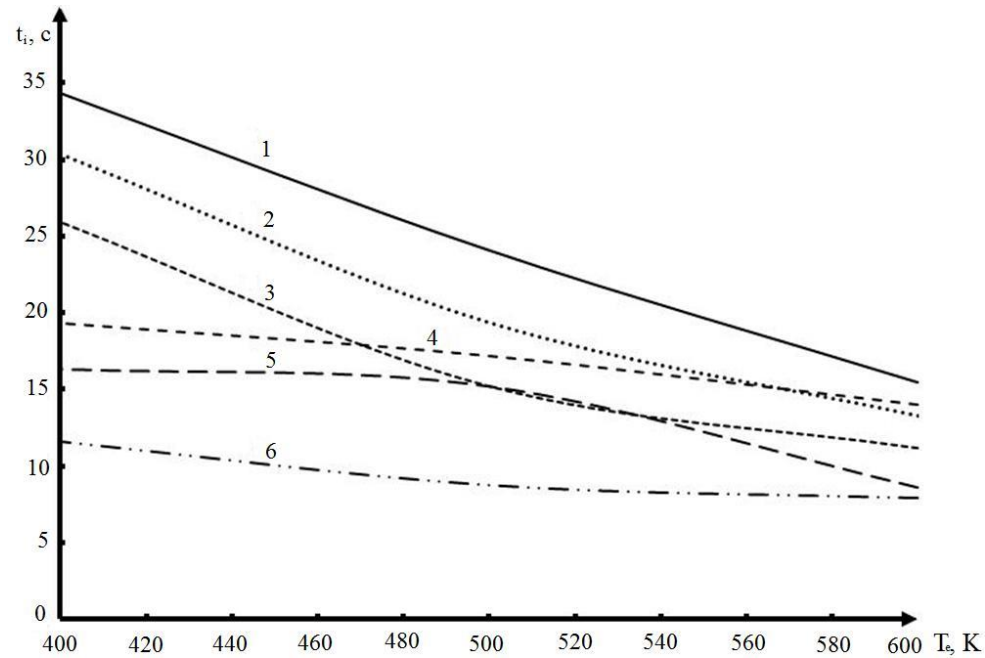

Figure 3. The dependence of the ignition delay WCF particles (diameter $\mathrm{d}=1,5 \div 2,5 \cdot 10-3 \mathrm{~m}$ ) and evaporation of the water film on the temperature in the oxidant stream flow velocities: $1-\mathrm{V}=0.8 \mathrm{~m} / \mathrm{s} ; 2-\mathrm{V}=1.8 \mathrm{~m} / \mathrm{s} ; 3-\mathrm{V}=3.8 \mathrm{~m} / \mathrm{s} ; 4-\mathrm{V}=0.8 \mathrm{~m} / \mathrm{s} ; 5-\mathrm{V}=1.4 \mathrm{~m} / \mathrm{s} ; 6-\mathrm{V}=3.8 \mathrm{~m} / \mathrm{s}$; $1 ; 2 ; 3$ - ignition delay times WCF particles; $4 ; 5 ; 6$ - times of the film evaporation. 


\section{MATEC Web of Conferences}

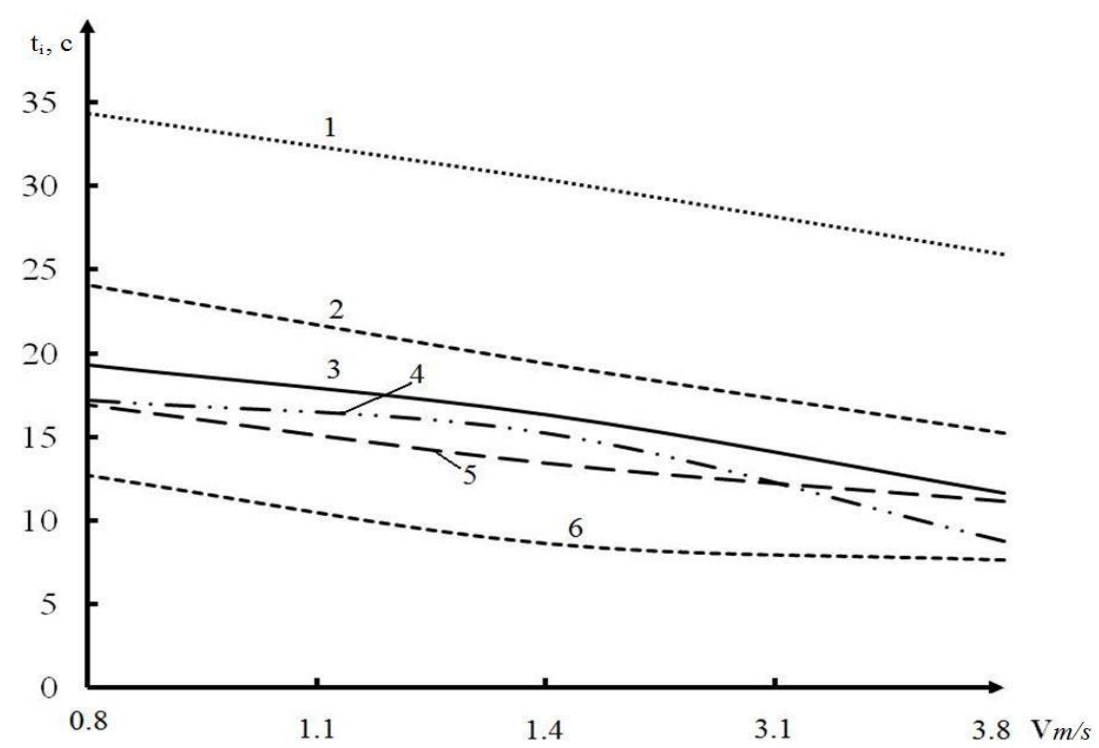

Figure 4.. The dependence of the ignition delay of coal-water particles (diameter $\mathrm{d}=1,5 \div 2,5 \cdot 10-3 \mathrm{~m}$ ) and evaporation of the water film on the flow velocity by varying the temperature of the outside: $1,3-\mathrm{T}=673 \mathrm{~K} ; 2,4-\mathrm{Te}=773 \mathrm{~K} ; 5,6-\mathrm{T}=873 \mathrm{~K} ; 1 ; 2 ; 5-$ ignition delay times WCF particles; $3 ; 4 ; 6$ - times of the film evaporation.

\section{Conclusion}

The temporal characteristics of the processes of preparation and thermal coal-water fuel ignition particles coated with a water film have been established by the results of the experimental studies. The analysis of dependencies $t_{i}\left(T_{e}\right)$ and $t_{i}(V)$ has showed that the evaporation of the surface layer of water has a significant impact on the dynamics of the processes of heat and mass transfer in the ignition droplet WCF. The time of film evaporation takes between $20 \%$ to $50 \%$ of the induction period. On the basis of experimental studies it is possible to develop a mathematical model describing the complex thermal and thermochemical processes of heat and mass transfer in the induction period and the ignition of particles of complex structured and essentially inhomogeneous fuels like WCF.

This work was supported by the Russian Science Foundation (project 15-19-10003).

\section{References}

1. J. K. Kaldellis, D. Zafirakis, Renewable Energy, 7, 36 (2011)

2. Sanz-Casado Elias, Maria Luisa Lascurain and etc., Renewable Energy, 68 (2014)

3. Renewable energy sources, Energy Policy 35, (2007)

4. H. Camblong, I.M. de Alegria, M. Rodriguez, Energy Convers. Manage, 47, (2006)

5. J.P. Longwell, E.S. Rubin, J. Wilson, In Energy and Progress Combustion Science, 4, 21 (1995)

6. Lei Chen, Sze Zheng Yong, Ahmed F. Ghoniem, Prog. Energy Combust. Sci., 2, 38 (2012)

7. Bo Leckner, Prog. Energy Combust. Sci., 1, 24, (1998)

8. Alessandro Franco R. Diaz Ana, Energy, 3, 34 (2009)

9. Yiguang Ju, Wenting Sun, Prog. Energy Combust. Sci., 48 (2015)

10. J.S. Dennis., A.N. Hayhurst., S.A. Scott, Combust. Flame, 3, 147 (2006)

11. Agnieszka Kijo - Kleczkowska, Fuel, 90, (2011).

12. Wadys aw Gajewski, Agnieszka Kijo-Kleczkowska, Jacek Leszczyn, Fuel, 88, (2009)

13. V.V. Salomatov . I.V. Kravchenko. Burning and plasma chemistry: Part.1, Part.2, 3, 5 (2007), Part.3, 1, Part.4, 3, 6 (2008)

14. Huang Z. et all. Proc. 8-th Intern. Symp. Coal Slurry Fuels Preparation and Utilization (USA, Orlando, 1986)

15. K.J. Matthews, A.R. Jones, Proc. 8-th Intern. Symp. Coal Slurry Fuels Preparation and Utilization (USA, Orlando, 1986)

16. G.V. Kuznetsov, V.V. Salomatov, S.V. Syrodoy, Combustion, Explosion and Shock Waves, 4, 51 (2015)

17. G.V. Kuznetsov, V.V. Salomatov, S.V. Syrodoy, Thermal Engineering, 10, 62 (2015)

18. S.V. Syrodoy, G.V. Kuznetsov, V.V. Salomatov, Solid Fuel Chemistry, 6, 49 (2015)

19. U.A. Senchurova, V.I. Murko, I.A. Fedyaev, Bulliten of the Tomsk Polytechnic University, 4, 312 (2008) 